\title{
Arte e psicanálise: Uma nova abordagem sobre a subjetividade na cultura contemporânea
} Art and psychoanalysis: A new approach on subjectivity in the contemporary culture

Ana Carolina Nunes Silva ${ }^{1}$ 


\section{Resumo}

Neste presente trabalho, veremos por meio das análises do filósofo esloveno Slavoj Žižek e do historiador da arte Hal Foster, a importância de pensar a imbricação entre subjetividade e cultura através da psicanálise, já que o sujeito desta instância do saber se constitui a partir de sua exterioridade (Outro). Em sua potência crítica, a psicanálise pode acompanhar e acentuar a crise que conforma sujeito e cultura, de modo a assumir um papel na contínua transformação de ambos. O diálogo entre arte e psicanálise pode tornar inteligivel "nosso tempo" para fazer ressoar o inatual, isto é, para tornar artificial aquilo que foge à compreensão imediata, convidando-nos a uma reflexão mais ampla. A arte contemporânea agencia intervenções críticas na cultura, convidando a experiências de subversão - e de reflexões sobre o sujeito e o mundo, entrecruzandose com a psicanálise e a filosofia, entre outros campos do saber.

Palavras-chave: Arte Contemporânea. Psicanálise. Subjetividade. Crítica.

\section{Abstract}

On this paper, we'll see by means of the analysis of the Sloveninan philosopher Slavoj Žižek and the art historian Hal Foster, the importance of thinking the imbrication between subjetivity and culture through psychoanalysis, since the subject from this knowledg instance is made of his or her externality (Other). In its criticism potencial, the psychoanalysis can accompany and punctuate the crisis that forms subject and culture, in order to assume a role in both's continuous changing process. The dialog between arts and psychoanalysis can turn into comprehensible "our time" to resound the unpresent, this is, to make artificial what escapes immediate comprehension, invinting us to a greater reflection. Contemporary art agences critical interventions in culture, inviting to subversion experiences - and reflection about the subject and the world, mutually crossing psychoanalysis and philosophy, among other knowledge areas.

Keywords: Contemporary Art. Psychoanalysis. Subjetivity. Criticism.

ISSN: 2175-2346

\footnotetext{
${ }^{1}$ Ana Caroline Nunes Silva

Mestre em Estética e Filosofia da Arte pelo Programa de Pós-Graduação em Estética e Filosofia da Arte do Instituto de Filosofia, Artes e Cultura- IFAC/ UFOP.

lacarolitanunes@gmail.com
} 


\section{Introdução}

Nota-se que os termos psicanalíticos entraram no vocabulário da teoria e da crítica de arte. A relação entre arte e psicanálise é uma forma de reconstituição do sujeito, pois este está no centro da questão da arte. A subjetividade, segundo Žižek, é considerada uma estrutura incompleta, que consiste em uma alternância de antecipações e reconstruções de acontecimentos traumáticos. Seguindo a intuição zizekiana, é nessa concepção de subjetividade que o historiador da arte Hal Foster baseia seus estudos da estética do final do século XX, como forma de produzir outra abordagem da relação entre teoria e arte, aplicando um modelo mais sofisticado e complexo de "subjetividade". Foster busca analisar a coordenação dos eixos histórico e social da arte e da teoria por meio da psicanálise, enfatizando, sobretudo, como também o fez Žižek, as formulações psicanalíticas de Jacques Lacan.

A vanguarda histórica e a neovanguarda estão constituídas de maneira análoga à constituição do sujeito para a psicanálise. Elas representam uma complexa alternância de "futuros antecipados" e "passados reconstruídos". E a obra de arte vanguardista, por sua vez, nunca foi historicamente eficaz ou plenamente significante em seus momentos iniciais, nem nunca poderia ter sido. Em outras palavras, a obra de arte moderna é traumática, pois nos revela o buraco da ordem simbólica de seu tempo. Este trauma ou desestruturação da interpretação aponta para a outra função da repetição dos acontecimentos vanguardistas, como acontece com o ready-made. A ressignificação pode não somente se estabelecer a partir de tais buracos, mas também pode cobri-los - como a psicanálise já indicara, pois a repetição é um grande meio de afastar-se do trauma. Mas como vamos distinguir essas duas operações, a primeira destruidora e a segunda restauradora? Essa é, segundo Foster, a grande questão da arte de nosso tempo.

Para melhor compreensão do tema, retomemos a metapsicologia lacaniana de Real-Simbólico-Imaginário que dá base aos comentários de Žižek e Foster. Lacan configura o conceito de "Real" com respeito a outras duas dimensões básicas: o Simbólico e o Imaginário; e é justamente essa estrutura que constitui os sujeitos. Para Lacan, o que chamamos de "realidade" articula-se através da dimensão Simbólica e da dimensão do Imaginário, que funcionam dentro da ordem da significação. O Imaginário pode ser visto como um caso especial da significação, pois enquanto o Simbólico é aberto, o Imaginário, por sua vez, procura domesticar tal abertura pela imposição de uma imagem fantasística de acordo com cada indivíduo; ou seja, o Imaginário é uma dimensão que prende o Simbólico em torno de certas fantasias fundamentais. Mas Lacan insiste que a experiência humana não é somente guiada por imagens ordenadoras (Imaginário) e por estruturas sociossimbólicas (Simbólico) que visam a garantir a identidade, mas também por uma ruptura, a saber, pela dimensão Real. O Real é um campo de experiências subjetivas que não podem ser simbolizadas por imagens fantasmáticas, e 
por isso, segundo Lacan, ele é "negativo" 2. Em contraste com as outras dimensões, o Real não pertence à ordem (simbólico-imaginária) da significação, mas é exatamente aquilo que a nega, aquilo que não pode ser incorporado a essa ordem. É isso que Lacan chamaria de não-virtualizável.

Em outras palavras, o Real persiste como dimensão persistente da falta de recobrimento, e toda construção simbólico-imaginária existe como uma certa resposta histórica do sujeito a essa falta básica. O Real sempre funciona de modo a impor limites de negação a qualquer ordem significante (discursiva), mas pode ser responsável também pela reconfiguração de tal ordem. Nesse sentido, o Real é estritamente inerente à significação; ele é tanto a negatividade de qualquer sistema de significação, quanto sua própria condição de possibilidade. Toda forma de "realidade" (simbólica/imaginária) existe como tentativa não inteiramente bem sucedida de escapar às várias manifestações do Real que ameaçam nossa desintegração: trauma, perda, angústia etc. Buscando uma analogia na arte, poderíamos dizer que esse conceito de Real funciona como "ponto de fuga", isto é, como algo que não pode ser representado, mas, mesmo assim, é constitutivo da representação. Nesse sentido, poderíamos dizer que o Real como ponto de fuga visual é o próprio sujeito da arte.

\section{A arte da razão cínica: fetichismo, crítica e cumplicidade.}

O termo "arte da razão cínica"3 desenvolvido por Foster, refere-se, precisamente, aos protocolos estéticos dos movimentos artísticos que surgiram após os anos 1960, cujas obras incorporaram materiais e procedimentos estéticos que foram alvo de crítica na primeira metade do século XX. O plano estético-crítico das vanguardas modernas calcou-se na estetização do discurso de "recusa à mimesis" como forma de manter uma "correta distância" da realidade social em que a ideologia dominante operava com toda a sua brutalidade. Desse modo, como bem observou Safatle, na arte contemporânea encontramos um certo

esgotamento da crítica que estaria exposto de maneira mais clara nas transformações da relação crítica entre arte e domínios hiperfetichizados da cultura (publicidade, moda, musica tonal, quadrinhos, pornografia, etc.) em relações de "cumplicidade desafiadora", como diria o simulacionista Ashley Bickerton. Relações nas quais a crítica como "distância correta" a respeito da fascinação fetichista parece entrar definitivamente em colapso em prol da elevação da mera repetição de conteúdos

\footnotetext{
2 Žižek ilustra precisamente essa tríade com um jogo de xadrez: "as regras que temos de seguir para jogar são sua dimensão simbólica: do ponto de vista simbólico puramente formal, "cavalo" é definido apenas pelos movimentos que essa figura pode fazer". Esse nível é claramente diferente do imaginário, a saber, o modo como as diferentes peças são moldadas e caracterizadas por seus nomes (rei, rainha, cavalo), e é fácil imaginar um jogo com as mesmas regras, mas com um imaginário diferente, em que esta figura seria chamada de "mensageiro", ou de "corredor", ou de qualquer outro nome. Por fim, o real é toda série complexa de circunstâncias contingentes que afetam o curso do jogo: a inteligência dos jogadores, os acontecimentos imprevisíveis que podem confundir um jogador ou encerrar imediatamente o jogo (ŽIŽEK, 2010, p.16).
}

3 Tal conceito abordado por Hal Foster no campo da teoria da arte, é oriundo do pensamento Peter Sloterdjik em sua Crítica da Razão Cínica (1983) $\square$ polêmica obra publicada dias depois que de comemorado o ducentésimo aniversário da publicação da Crítica da Razão Pura (1781), de Immanuel Kant. Nessa reflexão, mostraremos como encontramos o cinismo, pensado pela primeira vez, como uma estrutura de racionalidade que opera como inversão daquela concepção tradicional marxista de ideologia que a concebia como uma "falsa consciência" no domínio das relações reificadas, que constitui uma aparência socialmente necessária e como uma "alienação" incapaz de compreender a totalidade das estruturas causais que suportam as reproduções sociais. A razão cínica é a falsa consciência esclarecida. 
hiperfetichizados a esquema geral da produção artística. Tal colapso tem como resultado maior o advento acerca de certa estetização da razão cínica (SAFATLE, 2008, p.179).

A crítica zizekiana do cinismo no campo social4, bem como a crítica de Foster no campo das artes, nos possibilitaram levar mais a fundo a discussão da questão da arte dentro dessa estrutura de racionalidade. O tema do "esgotamento da forma crítica" na esfera da arte, apresentado pelo comentário de Safatle, é trazido como desidentificação desse fenômeno com a possibilidade da ideia de crise, ou, mais especificamente, com a ideia de declínio da crítica. Se o "esgotamento da forma crítica" passou por mudanças compreendidas pelas sucessões de valores estéticos, pode-se afirmar que as novas visões de crítica de arte acompanharam as mudanças de compreensão das obras a partir das determinações de seus esquemas constitutivos.

Partindo da perspectiva do modernismo, Safatle retoma a compreensão da crítica hegemônica desse movimento artístico, que é essencialmente configurada pelo distanciamento e negação da representação mimética, pois esta seria a expressão em que se manifesta a vigência de ideologias. Portanto, de acordo com Safatle, a arte moderna se constitui através de um esforço premente de desalienação de seus próprios mecanismos de produção de sentido. Desse modo, a autonomia da forma seria, por definição, a possibilidade de tematizar o próprio processo de produção artística.

Por essa via, o cinismo corresponderia a um apelo à "transparência" da arte em seu próprio material, realizando o desvelamento ou, talvez, melhor dizendo, decompondo a relação fetichista no interior de si mesma. No caso, o esgotamento de uma forma crítica implica, na visão de Safatle, uma transposição que preserve certa dimensão de exterioridade, o "correto distanciamento" 5, para que a crítica se reformule como tal. A mudança do enfoque crítico, por sua vez, tem sua referência nas formas de produção artística em suas relações com a realidade social, porque ela introduz um ponto específico que não é nem cinismo, nem o esgotamento de uma forma crítica, e sim a mudança de enfoque.

Levada ao esgotamento, a racionalização estética, como crítica de distanciamento e negação dos aspectos fetichizados da sociedade, toma, especialmente a partir da década de 1960, uma direção alternativa em que a própria realidade fetichizada se revela como espaço para a autocrítica. Isso porque a arte retoma a mímesis como uma possibilidade de "retratação" da realidade social impregnada de componentes fetichistas em sua ideologia, mas, ao mesmo tempo, esta própria ideologia já teria incorporado a si a crítica como forma de buscar a desobstrução da alienação: "[...] a ideologia já opera, a todo momento, uma distância reflexiva em relação àquilo que ela própria 
enuncia. Ou seja, a forma crítica (da racionalização estética) esgotou-se porque a realidade internalizou as estratégias da crítica" (SAFATLE, 2008, p. 196). Nas palavras de Tânia Rivera:

Não há mais uma clara distância entre produção e crítica a partir do momento em que a própria produção artística assume como cerne de sua poética uma dimensão crítica, ou seja, põe-se a quebrar (krinein, em grego), a pôr em crise os parâmetros culturais definitórios da arte (RIVERA, 2013, p.182).

\section{O declínio da arte "antifetichista".}

Voltando à perspectiva do pensamento fosteriano, nas artes visuais da primeira metade do século XX havia uma tensão entre crítica e convencionalismo. Diante desse aspecto, muitos artistas começaram a adotar uma postura "cínica" como forma de negociar as contradições que rodeavam o universo artístico desse período. $\mathrm{E}$ a arte apropriacionista, por sua vez, operava como resultado de uma tensão entre crítica ideológica e desconstrução dos padrões tradicionais nos protocolos de constituição da arte moderna.

Através de Foster, percebemos que a própria história das vanguardas já apontava para uma profunda mortificação da crítica. Pois as vanguardas, em contexto capitalista, produziram vários modelos de análise que foram insuficientes para superar a cultura dominante. Ainda que se definisse contra a burguesia, elas representavam a elite "autocrítica" dessa classe, porque é imprescindível para a crítica certo compromisso com a cultura dominante. Nesse contexto, para um artista de vanguarda era essencial certa identificação com seu mecenas, como uma forma de atrair o inimigo para seu lado. Mas logo a arte apropriacionista fez com que esse compromisso com a cultura dominante se convertesse em total identificação com essa classe, e dessa maneira, artistas e mecenas passaram a considerar a arte como um signo-mercadoria de troca, e o mercado artístico abrigou as práticas que refletiam seus próprios convencionalismos.

Nesta situação, muitos artistas se voltaram contra a "arte crítica" como se esta fosse traidora e, diante das demandas contraditórias entre propor a transformação crítica na arte e demonstrar a futilidade desse projeto, alguns artistas recorreram a uma postura esquizofrênica característica da razão cínica. Na visão de Foster:

O que a estética da razão cínica poderia nos dizer a esse respeito? Obviamente, qualquer narrativa de uma criticalidade derrocada é suspeita, pelo menos quando é apresentada como consumada. A arte do pós-guerra geralmente espelha a cultura dominante: de certa maneira a pintura color-field reiterava a lógica do design coletivo; o minimalismo e a pop, a lógica do consumo diferencial; a arte conceitual, a lógica da sociedade administrada, e assim por diante. Esses espelhamentos, em si mesmos, pouco provam. A crítica (que não é menos mimética que o desejo) precisa de algum engajamento da cultura dominante, e à vanguarda é essencial certa identificação com seus mecenas (FOSTER, 2014, p.118).

Assim como Žižek, Foster alega que o grande fator do declínio da "arte crítica" é 
sua dependência da desmistificação. A Escola de Frankfurt acreditava que a crítica através da arte poderia construir a consciência dos mecanismos de dominação, tornando o espectador um agente consciente de transformação da realidade social. No entanto, na racionalidade cínica, as verdades nem sempre estão escondidas; ao contrário, muitas vezes estão evidentes - mas uma evidência que bloqueia a reação:

"Eu sei que os museus têm mais a ver com o capital financeiro do que com a cultura pública, porém..." Como uma operação fetichista de reconhecimento e repúdio (“Eu sei, mas ainda...”), a razão cínica também é objeto para a crítica antifetichista6.

Pensar um objeto de arte que pode perceber por nós e trazer a consciência de nossa realidade é também uma fetichização, pois processa pensamentos e sentimentos em imagens ou efeitos para nossa fruição.

\section{Andy Warhol e o sublime objeto da ideologia.}

Tal postura foi evidenciada por Foster através do grande precursor da pop art nos Estados Unidos, o artista Andy Warhol, que triunfou ao personificar o "sonho americano" em sua arte. A visão referencial do pop warholiano foi vista como ambígua e paradoxal por alguns críticos e historiadores da arte. Por um lado, Warhol foi considerado um artista de engajamento político, que expressava certo incômodo perante a superfície glamourosa do fetiche das mercadorias e das estrelas da mídia. Suas obras foram consideradas um palco de crítica do "[...] consumo complacente por meio de um fato brutal do acidente e da mortalidade" (FOSTER, 2014, p.124), como as imagens expostas em Death and Disaster, no início dos anos 60. Essa exposição compõe-se de uma série de trabalhos que mostra a violência nos Estados Unidos durante os anos 1960, e se torna mais impactante por conta da uniformidade da cor que o artista aplica nas obras. São imagens representando pessoas comuns que se jogaram do alto de edifícios ou foram mortas em acidentes automobilísticos e negros violentamente atacados por cães da polícia durante confrontos sociais7.

Com essas imagens, Warhol foi considerado um artista que se sentia atingido pelos males da política americana e que expunha seus sentimentos humanistas em direção ao engajamento político. Ao mesmo tempo, a produção do artista foi considerada "superficial" e sua postura "indiferente" às mazelas da sociedade, pois suas obras representavam o "fim da subversão" vanguardista, uma vez que estavam integradas à economia política da sociedade de consumo. Ora, nesse contexto uma questão se faz muito relevante: Andy Warhol praticava uma ironia cínica (no sentido de Kynismus) ou uma razão cínica? Nesse aspecto, Foster, em continuidade com Žižek e mais uma vez contra Peter Sloterdijk, acredita que tal delimitação é um tanto obsoleta, já que tais

\footnotetext{
6 FOSTER, H. Pós-Crítica. Disponível em: http://www.ppgav.eba.ufrj.br/wpcontent/uploads/2013/12/ae25_hal.pdf

7 Entre os trabalhos desta série estão: Little Electric Chair (1964), Five Deaths (1963) e Suicide (1963) $\bullet$
} 
posições, dentro de um contexto niilista proporcionado pelo capitalismo contemporâneo, já não se diferem uma da outra. De todo modo, a perspectiva apresenta Warhol como cúmplice do sistema capitalista e pode ser apenas uma projeção de nossa visão de mundo, pois Warhol, assim como os demais artistas pop, por mais que fizesse críticas a sua realidade efetiva, representava o mundo que o fascinava.

A postura ambígua de Warhol é análoga àquela retratada por Diderot em $O$ sobrinho de Rameau: um sujeito que "ri da nobreza, ao mesmo tempo que desfrutava dela". No entanto, Warhol não foi dos que viveram um certo descompasso entre o discurso e sua prática, como o sobrinho, mas viveu intensamente seu discurso, estetizando em suas obras diversas modalidades de funcionamento dos mecanismos ideológicos, ou seja, promovendo a estetização do político de sua realidade social. Talvez possamos entender o núcleo dessa ambiguidade em relação às obras de Warhol em termos de paralaxe (o deslocamento aparente de um objeto causado pelo movimento real do observador).

A forma com que o artista representou o American way of life em suas obras foi tomado, no contexto das ditaduras da América Latina, como uma instância de crítica. Com isso, a ideia de fazer pop art no Brasil, em um contexto de mobilização política pelos movimentos estudantis e de mobilização cultural pela produção artística brasileira dos anos 1960-70, convergiu para ideais de revolta ${ }^{8}$. Esse é o aspecto fundamental da ideologia cínica: o mesmo elemento que serve de fetiche pode ser uma crítica, pois ela é capaz de transformar um excremento em objeto sublime. Segundo Žižek em seu filme The Pervert's Guide to Ideology (2012), a ideologia opera através desse elemento "a-mais", que pode ser capaz de transformar uma Coca-Cola quente e intragável em objeto sublime.

O estabelecimento de uma relação com aquilo que Žižek chama de objeto sublime aparece então, como uma dimensão efetiva, presente, operante no que diz respeito à produção artística da segunda metade do século XX. E ainda no que se refere a uma relação com este objeto sublime - desta vez não circunscrita à esfera da produção artística - não podemos superar a fascinação produzida por ele sem entendermos o papel desse "a-mais", o excesso, em nossas vidas. Quando desvendamos esse elemento ideológico, ele cai e se torna um mero dejeto.

\section{A estetização do Real e o desejo de abjeção.}

Neste ponto de nossa discussão, cabe aqui um parêntese para entendermos os móbiles de crítica das vanguardas históricas e a constituição da arte contemporânea por meio da concepção psicanalítica do "Real". Segundo Žižek, uma certa paixão animou a história do século passado; trata-se de uma paixão pelo desvelamento do Real

\footnotetext{
8 Em outubro de 2012 aconteceu a exposição intitulada "América do Sul, a Pop Arte das Contradições", com curadoria de Paulo Herkenhoff e Rodrigo Alonso, no museu Oscar Niemeyer da cidade de Curitiba/Paraná, em que se mostrava a diferença entre a concepção estética do pop brasileiro e a da vertente americana da mesma corrente, e a visão de engajamento político que os artistas brasileiros tinham desse movimento
} 
coberto pelo véu da realidade.

Ao contrário do século XIX dos projetos e ideais utópicos ou científicos, dos planos para o futuro, o século XX buscou a Coisa em si - a realização direta da esperada Nova Ordem. O momento último e definidor do século XX foi a experiência direta do Real como oposição à realidade social diária - o Real em sua violência extrema como preço a ser pago pela retirada das camadas enganadoras da realidade (ŽIŽEK, 2008, p.22).

Tal experiência direta do Real nos auxilia na compreensão de certas teorias políticas desse momento que buscaram fazer uma crítica à alienação ideológica -como, por exemplo, as vanguardas artísticas desse período em sua crítica aos valores de representação; e a mimesis da realidade como possibilidade de fazer emergir o Real obnubilado pela realidade social hiperfetichizada. A paixão pelo Real, na perspectiva de Žižek, é uma espécie de desejo de ruptura da aparência através da transgressão do simbólico, do espectro, da crença que sustenta nossa realidade socialmente compartilhada, como forma de instaurar uma outra realidade a partir da ordem do Real. No entanto,

se a paixão pelo Real termina no puro semblante do espetacular efeito do Real, então, em exata inversão, a paixão pós-moderna pelo semblante termina numa volta violenta à paixão pelo Real (ŽIŽEK, 2008, p.26).

Žižek não abandona nenhum tipo de operação crítica desse viés, mas devemos entender o problema dessa busca autodestrutiva pelo Real, pois essa paixão pelo real, tal como a concebe Žižek, não é mais que a substituição do confronto com o Real traumático pela crença em uma estrutura espetacular metafísica e redentora. É por isso que Žižek insiste na existência de uma fantasia ideológica, como forma de recuperar a temática de crítica da ideologia. Afinal, a ideologia produz encobrimentos e opera segundo a mesma estratégia da fantasia. Em outras palavras, ela utilizaria os mesmos protocolos de produção fantasística e também trabalharia com as mesmas ilusões metafísicas de superação.

O conceito de fantasia, tal como formulado no discurso psicanalítico, seria uma espécie de camada pacificadora dessa esfera traumática e vazia do real como forma de não confrontá-lo9. Tal concepção estético-política zizekiana é oriunda das análises que Alain Badiou faz em $O$ século (2007), obra em que se discute a ideia de que, no século XX, o semblante tornou-se o verdadeiro princípio de situação do Real, isto é, o ponto catalizador das contingências do Real. Sob o ponto de vista de Badiou, nunca, em nenhum momento da história, se pensou tanto a relação entre "[...] violência real e o aparente semblante, entre rosto e máscara, entre nudez e travestimento. Encontramos esse aspecto nos mais variados registros, indo da teoria à prática artística" (BA- 
DIOU, 2007, p.81). Será a partir dessa concepção de Real que encontraremos a operação ideológica como algo ligado à união entre marxismo e psicanálise no século XX: a ideologia é um encobrimento do Real, uma interpelação do sujeito, como no efeito imaginário das formações inconscientes na psicanálise ${ }^{10}$. Em outras palavras:

O século expõe o motivo da eficácia do desconhecimento enquanto o positivismo do século XIX afirmava o poder do conhecimento. Contra o otimismo do positivismo, o século XX descobre e coloca em cena o extraordinário poder da ignorância, daquilo que Lacan nomeia com justa razão como a "paixão pela ignorância" (BADIOU, 2007, p.83).

Tal aspecto tornou-se o axioma da arte de vanguarda, isto é, de tomar o Real como eficácia do semblante. É por isso que a arte de vanguarda foi considerada uma arte reflexiva, como aquela que queria "[...] idealizar visivelmente sua materialidade" (BADIOU, 2007, p.84). Segundo Badiou, se a arte é o encontro de um Real pelos meios exibidos do factício, então a arte está por toda parte, já que toda a experiência humana é atravessada pela distância entre a dominação e a ideologia dominante, entre o Real e seu semblante. Isto é, em todas as partes da realidade social encontramos a experiência desta distância, e foi justamente por isso que o século XX pôde apresentar como arte o que anteriormente era mero dejeto ${ }^{11}$.

\section{O caráter ambivalente da estética do Real.}

Como já foi anteriormente mencionado neste trabalho, Žižek e Foster insistem numa leitura lacaniana da subjetividade, isto é, insistem na ideia de que a concepção de "sujeito" tornou-se bastante obsoleta, já que ela supostamente evoca a imagem de uma identidade cartesiana, ou de uma espécie de centro de subjetividade. Para Žižek, o sujeito não é uma entidade substancial, pois a existência do sujeito se dá através de uma dimensão eterna de resistência-excesso em relação a todas as formas de subjetivação. Em outras palavras, o sujeito é um vazio constitutivo básico que impulsiona a subjetivação, mas não pode ser preenchido por ela, já que ele é, simultaneamente, a falta e o que sobra de todos os processos de subjetivação.

\footnotetext{
10 A partir das análises psicanalíticas de Lacan, Badiou afirma que a palavra "inconsciente" designa precisamente o conjunto das operações pelas quais o real de um sujeito não é conscientemente acessível, a não ser na construção íntima e imaginária do Eu [Moi]. Nesse sentido, a psicologia da consciência é ideologia pessoal, que Lacan nomeia como o "mito individual neurótico". Existe uma função de desconhecimento que faz com que o abrupto do real opere apenas em ficções, montagens, máscaras (BADIOU, 2007, p. 83).

11 Diante desse aspecto, Badiou indaga: qual é a função do semblante na paixão pelo real? A importância do semblante é o artifício de poder manifestar o real através de máscaras,; ele somente pode ser ficcionado: "o real, tal como concebido em sua absolutidade contingente, nunca é bastante real para não se suspeitar que seja semblante" (BADIOU, 2007, p.89). No entanto, ressalta Badiou, "não temos presente qualquer critério formal que permita distinguir 0 real do semblante. Na ausência desse critério, a lógica que se impõe é que
}

quanto mais uma convicção subjetiva se apresenta como real, tanto mais é preciso desconfiar dela. Qual é a única coisa segura? O nada. Apenas o nada não é suspeito, já que não tem intenção de nenhum real. Daí resulta que nosso século, animado pela paixão pelo real, foi de todas as maneiras, e não somente em política, o século da destruição ou subtração" (BADIOU, 2007, p.90). 
A arte contemporânea é marcada por um verdadeiro "retorno ao sujeito" ou por aquilo que Foster, em sua obra, denominou de "retorno do real". Mas o sujeito que retorna na arte contemporânea tem suas fronteiras em relação ao Outro ${ }^{12}$ desmaterializadas, exigindo uma certa reconfiguração de suas relações consigo mesmo, com os objetos e com o espaço que o circunda. É uma espécie de "estetização" da "presença traumática do sujeito" na arte, pois na experiência do trauma não há mais um "eu" delimitado (como já foi dito), mas a de um sujeito instável e efêmero (o sujeito do inconsciente), e é justamente nessa experiência que ele se constitui. Foster nos apresenta diversas categorias que poderíamos denominar de "estética do real": o realismo traumático, o hiperrealismo, a arte apropriacionista e a arte abjeta.

O Real, segundo Foster, retorna na arte contemporânea como o oposto da realidade mimética representada de forma ilusionista, especialmente no que diz respeito à pop art. Com a psicanálise, a realidade não é mais concebida a partir de um olho fixo e soberano capaz de ordenar a representação em regras fixas, pois o sujeito operante é entendido como "descentrado". Segundo Lacan, o sujeito é descentrado por constituir-se através da discordância entre o Eu produzido pela imagem ideal do Outro e seu "ser". Afinal, como em toda constituição das subjetividades no processo social, os sujeitos devem recalcar no interior de si mesmos sua essência, que não é um Eu. Tal ideia é análoga à concepção freudiana de que todo processo de socialização é uma repressão das pulsões para adequar-se à ordem social.

Grande parte das obras contemporâneas buscou unir o imaginário e o simbólico contra o Real. Nessa linhagem, Foster alega que o superrealismo representado pela pop art gera uma espécie de "momento ansioso", causado por seu ilusionismo excessivo, que nada mais é que um processo de encobrimento do Real, ainda que esse processo possa, ao mesmo tempo, apontar para ele. Adorno e Horkheimer identificavam na Indústria Cultural uma intenção de anestesiar o espectador de modo que não houvesse mais lugar para a experiência do sofrimento e sua expressão. Do mesmo modo, nas obras de Andy Warhol não há interesse de desenvolver a autonomia da subjetividade de seus espectadores, como Warhol mesmo afirmava; nelas, a experiência do sofrimento daria lugar a uma espécie de entorpecimento dos indivíduos com a repetição de imagens, que, por sua vez, impediria os indivíduos de pensar com profundidade sobre os fatos trágicos das imagens que permeiam sua realidade social.

A repetição em Warhol, assinala Foster, não é uma reprodução no sentido da representação (de um referente) ou simulação (de uma pura imagem); ela é uma forma de proteção contra o Real traumático. Mas exatamente essa necessidade da repetição pode também romper o anteparo proveniente da repetição, apontando para o Real.

Nestas imagens do começo da carreira de Warhol, alega Foster, vemos o que é sonhar a vida e o tempo na era da televisão - ou, antes, o que é ter pesadelo enquanto vítima que se prepara para desastres que já chegaram, pois ele seleciona momentos em

\footnotetext{
12 Digamos por ora que o grande Outro é um conceito designado por Lacan para indicar a substância social ou um "padrão" para tudo aquilo em virtude do qual o sujeito nunca tem pleno domínio dos efeitos de seus atos. Desse modo, o saldo final de sua ação seria algo sempre diferente daquilo que ele pretendia.
} 
que a sociedade do espetáculo do pós-guerra, os meios de comunicação de massa e as mercadorias se racham, mas para se expandir. Segundo Foster:

diferentes tipos de repetição estão em jogo em Warhol: repetições que se fixam no real traumático, que o encobrem, que o produzem. E essa multiplicidade contribui para o paradoxo não só de imagens que são ao mesmo tempo afetivas e sem afeto, mas também de observadores que não estão nem integrados (o que é o ideal da maioria das estéticas modernas: o sujeito tranquilo em contemplação) nem dissolvidos (o que é efeito de grande parte da cultura popular: o sujeito entregue às intensidades esquizofrênicas do signo-mercadoria) (FOSTER, 2014, p.130).

Assim como a arte do realismo traumático, a arte hiperrealista ${ }^{13}$ está também relacionada com o Real. No entanto, o hiperrealismo quer esconder mais do que revelar o Real e, com isso, constitui camadas de signos retirados do mundo do consumo não só contra a profundidade representacional, mas também como uma espécie de subterfúgio contra o real ${ }^{14}$. Isso significa que o hiperrealismo é uma arte empenhada não só em pacificar o Real, mas também em escondê-lo atrás da superfície, revelando-nos a realidade como uma simples aparência, uma ficção.

Ou seja, esse processo é uma forma de desrealizar o Real com efeito de simulacro, como nas pinturas pop de Warhol e de James Rosenquit, exemplifica Foster. É difícil imaginar o hiperrealismo, assim como o pop, apartado das superfícies fluidas do espetáculo capitalista.

Foster apresenta tal aspecto através das obras Richard Prince ${ }^{15}$, cujas imagens levam o espectador a uma experiência alucinatória diante do fascínio hiperrealista que se traduz em uma confusão entre sujeito e imagem, "dentro" e "fora" da fantasia consumista. Esta constituição da realidade por meio do hiperrealismo é a constituição básica da arte contemporânea: o sujeito guiado pelos ditames da ordem simbólica. Prince alega que seus anúncios não revelam nenhuma experiência subjetiva de si mesmo, somente transformam tais imagens encontradas na cultura americana e as repetem, produzindo o "novo" ao repeti-las de "novo". Esta ambiguidade das obras de Prince

\footnotetext{
13 A arte do Hiperrealismo (1970), também conhecida como "fotorrealismo", "superrealismo" ou "realismo radical", constitui a vertente americana do movimento "neorrealista". Tal movimento inspirou-se na iconografia e na tendência do uso de fotografias característicos da pop art. Os artistas hiperrealistas utilizavam frequentemente aérografo e recorriam à projeção sobre as telas de diapositivos que continham as imagens a serem reproduzidas. 0 caráter fotográfico dessa linguagem imprimiu-Ihe uma qualidade trompe-l'oeil que a tornava especialmente adequada para a criação de pinturas ilusórias. Disponível em: http://www.infopedia.pt/\$hiper-realismo.

14 Tais categorias de arte contemporânea apontadas por Foster colocam 0 espectador de dois modos distintos: o hiperrealismo convida o espectador a deleitar-se quase esquizofrenicamente em suas superfícies; já a arte apropriacionista, em seu procedimento de desmascaramento da ilusão, convida o espectador a observar sua superfície criticamente. No entanto, muitas vezes as duas se intercruzam, principalmente, quando a arte apropriacionista envolve o espectador em uma superfície hiperrealista. O mais importante ainda é que as duas formas se aproximam mutuamente neste aspecto: no hiperrealismo, a realidade é sobrecarregada pela aparência, enquanto a arte apropriacionista é construída na representação. Ambas utilizam a fotografia, mas o hiperrealis-
}

mo explora alguns valores fotográficos (como o ilusionismo) e põe em xeque valores pictóricos, como o da unicidade. Por outro lado, a arte apropriacionista utiliza a reprodutibilidade fotográfica para questionar a unicidade pictórica.

15 O artista Richard Prince nasceu em 1949 no Panamá. Em 1973, mudou-se para Nova York e conheceu a arte conceitual. Começou a trabalhar na Time -Life como preparador de recortes de revistas, e ali percebeu o potencial das imagens publicitárias como meio de expressão. Prince utiliza o conceito pop da apropriação e a descontextualização como ferramentas básicas, e toma emprestadas imagens anônimas do mundo publicitário para produzir "arte". $\mathrm{O}$ artista questiona os valores implícitos da obra de arte produzida depois da era da reprodução técnica, como a ideia de originalidade, de "objeto único" (aura), e o papel tradicional do artista que agora toma algo do mundo cotidiano e o transforma em objeto artístico. Por exemplo, a obra Cowboys (1984), em que explora a duvidosa preferência sexual desses conquistadores do velho oeste e também sua figura na propaganda publicitária para a Marlboro, cuja imagem buscava descrever a natureza norte-americana por meio do mito dos vaqueiros. Disponível em: http://culturacolectiva.com/richard-prince-el-chico -malo-del-arte-norteamericano/ 
pode conter sua potência crítica, pois nos mostra uma consciência cindida diante de uma imagem. Ao mesmo tempo, esse aspecto pode nos revelar outra versão do que Žižek chamaria de razão cínica. Desse modo, podemos enxergar a arte contemporânea como aquela que pode inferir uma crítica da imagem e, ao mesmo tempo, ser hostil a ela, ser fascinado por ela. Ou seja, contribui para o desmascaramento da ilusão, ao mesmo tempo em que faz o espectador ser sugado por essa ilusão.

Por meio de tais imagens, podemos perceber que Prince manipula a aparência hiperrealista de anúncios encontrados na cultura fetichizada capitalista ao ponto de desrealizá-los em sua aparência, mas de realizá-los na esfera do desejo.

\section{Despindo o objeto sublime.}

Como podemos perceber, a arte contemporânea está a serviço do Real; ela busca a possibilidade de uma representação do ob-sceno, do Real do objeto para o espectador. Além do fascínio pelo trauma, outro artifício que se pode perceber na arte contemporânea é o desejo de abjeção, de "degradação", do orgânico ou escatológico16.

Voltando ao pensamento zizekiano, na cena artística atual o Real não retorna sumariamente na forma da intrusão chocante e brutal de excrementos escatológicos ou cadáveres mutilados. Segundo Žižek, a "merda" é um excesso que não condiz com nossa realidade cotidiana, desse modo:

Lacan tinha razão quando afirmou que passamos de animais a humanos no momento em que o animal não sabe o que fazer com seus excrementos, no momento em que se tornam um excesso que o incomoda. (ŽIŽEK, 2009, p.163).

O surgimento de excrementos fora de seu lugar está, portanto, estritamente relacionado ao aparecimento do lugar sem nenhum objeto nele, da moldura vazia em si. Para melhor compreensão de tal análise, vejamos um exemplo que Žižek nos apresenta:

Nisso reside a cumplicidade entre dois ícones opostos do alto modernismo, o Quadrado negro sobre fundo branco, de Kazimir Malevitch, e a exposição de objetos ready-made de Marcel Duchamp como obras de arte. A noção fundamental de elevação de um objeto cotidiano comum a obra de arte em Malevitch é que ser uma obra de arte não é uma propriedade inerente ao objeto; é o próprio artista que, ao apropriar-se do (ou antes, de qualquer) objeto e colocá-lo em determinado lugar, transforma-o em obra de arte - ser uma obra de arte não é uma questão de "por quê", mas de "onde". E o que a disposição minimalista de Malevitch faz é simplesmente transformar - isolar - o lugar em si, o lugar vazio (ou a moldura) com a

\footnotetext{
${ }^{16} \mathrm{~A}$ arte abjeta foi uma categoria artística que se propagou internacionalmente nos anos 1990 e tematiza o orgânico e o escatológico. Tal concepção é derivada da noção psicanalítica de "abjeção", popularizada na contemporaneidade pela teórica francesa Julia Kristeva na década de 1980. "A noção de abjeto está ainda vinculada ao conceito de informe (ou formless, em inglês), desenvolvido décadas antes pelo escritor e pensador francês Georges Ba-
}

taille. Intrinsecamente ligada ao binômio "atração e repulsa", a arte abjeta é esteticamente pautada pelo apelo a uma organicidade intensa, com forte materialidade e muitas referências ao corpo e a suas secreções.": Cf. verbete do glossário online escrito por Guy Amado: http://novo.itaucultural.org.br/materiacontinuum/marco-abril-2009-arte-contemporanea/. 
propriedade protomágica de transformar qualquer objeto que se encontre em sua esfera em obra de arte. Em suma, não há Duchamp sem Malevitch: somente depois de o exercício da arte isolar o local/a moldura em si, esvaziar todo o seu conteúdo, é possível entregar-se ao ready-made. Antes de Malevitch, o urinol ainda seria um urinol, mesmo que fosse exposto na mais destacada galeria de arte (ŽIŽEK, 2009, p.163).

Para Žižek, o Real na arte contemporânea tem três dimensões, o que de certo modo repete no interior da realidade a tríade Imaginário-Simbólico-Real de Lacan. Aqui, o Real surge primeiro como a mancha anamórfica, como uma imagem torcida da realidade, pura aparência (semblance) que "subjetiviza" a realidade objetiva. Sendo assim, o Real aparece aqui como o lugar vazio, como uma estrutura, uma construção que nunca está ali e existe como tal, mas só pode ser construída retroativamente e precisa ser pressuposta como tal - o Real como construção simbólica. Desse modo:

o Real é o Objeto excrementício obsceno fora de lugar, o Real "em si". Esse último Real, se isolado, é um mero fetiche cuja presença fascinante/cativante mascara o Real estrutural, da mesma forma que, no antissemitismo nazista, o judeu como Objeto excrementício é o Real que mascara o intolerável Real "estrutural" do antagonismo social. Essas três dimensões do Real resultam de três modos de obter uma distância da realidade "comum": ou se submete essa realidade à distorção anamórfica, ou se introduz um objeto que não está em seu lugar ali, ou se subtrai/ apaga todo conteúdo (objetos) da realidade, para que todo o resto seja o próprio lugar vazio que esses objetos ocupavam antes (ŽIŽEK, 2009, p. 163).

O termo "obsceno" em nossa sociedade parece entrar em colapso, mas poderia ser esta uma das diferenças entre as definições do termo que encontramos em nossa cultura: o obsceno é onde o objeto, sem cena, está bastante próximo do espectador, enquanto o obsceno pornográfico é o momento em que o objeto é posto sobre a cena para o espectador, distanciando seu observador do objeto Real. Diversas obras contemporâneas apresentaram unicamente o obsceno; entretanto, boa parte delas somente o manipulou, pois o obsceno é a maior defesa contra o Real e não sua dissolução. Em suma, em um sistema de estruturas normativas duais como a do capitalismo atual, cujo sistema busca "dessublimar" ou transformar tudo em espetáculo, poderá a arte abjeta escapar de uma utilização instrumental e moralista em nossa sociedade? Poderia haver uma evocação do obsceno que não seja pornográfica?

A condição de abjeto nos leva a uma dimensão paradoxal entre a operação de abjeta e a condição de ser abjeto ${ }^{17}$. Kristeva, uma das grandes precursoras do tema, alega que a operação de abjetar é fundamental para a manutenção tanto do sujeito quanto da sociedade, apesar de a condição de ser abjeto poder ser corrosiva para ambos.

\footnotetext{
17 "Abjetar" significa: expulsar, separar; enquanto que ser "abjeto" é ser repul-

sivo, pondo a própria subjetividade em risco.
} 
Desse modo, poderíamos nos perguntar: o abjeto seria uma forma de perturbação da ordem subjetiva e social ou uma confirmação e normatização dessa ordem?

Aqui, o conceito de "ordem simbólica" é também de suma importância para pensarmos este aspecto, pois o valor da arte abjeta depende de sua posição. E desse modo, talvez devêssemos:

repensar a transgressão não como uma ruptura produzida por uma vanguarda heroica fora da ordem simbólica, mas como uma fratura traçada por uma vanguarda estratégica dentro da ordem. Desse ponto de vista, o objetivo da vanguarda não é, de maneira alguma, romper com essa ordem (esse sonho antigo está dissipado), mas expô-la em crise, registrar seus pontos não só de colapso [breakdown], mas de superação [breakthrough], as novas possibilidades que tal crise poderia abrir (FOSTER, 2014, p.148).

No entanto, em alguns momentos, a arte abjeta tomou posições distintas: a primeira consiste em identificar-se como abjeta, aproximar-se disso de alguma maneira, sondar a ferida do trauma, tocar o obsceno do Real; a segunda consiste em representar a condição de abjeção com o objetivo de provocar sua operação, apreender a abjeção no ato e torná-la reflexiva. Mas essa mimesis pode também reconfirmar uma abjeção dada e, com isso, o desgosto da abjeção pode ingressar no espetáculo e dar suporte à normatividade da ordem simbólica. Nos termos de Sloterdijk, tal aspecto pode ser kynica, pois leva a degradação a um ponto de denúncia social, ou cínica, pois o sujeito aceita essa degradação como autoproteção ou proveito.

\section{0 confronto dos Acionistas Vienenses com o status quo do cinismo.}

Podemos encontrar esta ambivalência da crítica da estética da abjeção nas performances dos anos 60, estágio no qual a arte não podia representar o corpo se não violado, atacado ou degradado. Para melhor compreensão desse fenômeno, temos o grupo de performances "Acionistas Vienenses" (1962), formado por Otto Mühl, Güter Brüs, Rudolf Schwarzkoger e Hermamm Nitsch, que tomou o horror e a obscenidade como elementos centrais de suas performances (produzindo filmes pornográficos de zoofilia, urofilia, coprofilia, expondo o público a uma série de situações tabus) ${ }^{18}$. Com um discurso do negativo, do intragável, do perverso, do obsceno, da luxúria, da histeria, os Acionistas Vienenses buscavam refletir a função da arte na sociedade contemporânea e, ao mesmo tempo, criticar e derrubar todos os tabus do ambiente ultraconservador austríaco dos anos 1960-7019.

Havia um desejo utópico de renovar radicalmente a arte, fazendo dela um instrumento de transformação da sociedade, de "purificação" das amarras do establish-

\footnotetext{
18 Em 1968, Mühl participa de uma performance intitulada "Art and revolution" de seu colega Güter Brus. Convidado a falar sobre a função da arte na sociedade capitalista a um grupo de estudantes na universidade de Viena, Brüs fica nu, urina, bebe a própria urina, entre outras coisas.

19 Conferir o artigo de Priscilla Ramos da Silva intitulado "Acionistas Vienenses: revolucionários ou perversos?". Disponivel em: http://pt.scribd.com/
} 
ment. Ao propagarem isso, os Acionistas Vienenses buscavam provocar a destruição da própria arte como força transformadora do status quo. No primeiro momento, os Acionistas Vienenses foram adentrando os cânones da história da arte com o estatuto de vanguarda 20 ou "revolucionários da arte", por mostrar como os valores daquela sociedade eram meros "abjetos". Por outro lado, as apresentações dos Acionistas Vienenses no mundo da arte foram consideradas, por parte da sociedade, como simples atos de perversão ou insanidade; os performers sofreram perseguição e foram muitas vezes detidos pela polícia devido à imoralidade de suas ações.

Anos mais tarde, Otto Mühl rompe relações com os demais Acionistas Vienenses e funda uma comunidade alternativa chamada Friedrechsholf em um castelo no interior da Áustria, que tinha como pressupostos básicos a propriedade coletiva, a sexualidade livre, a educação compartilhada das crianças. Mühl pretendia criar um experimento social e sexual em que a arte pudesse ser associada à vida, longe dos regulamentos do Estado. No entanto, como o sistema conservador que pretendia romper, o artista ditava algumas regras de convivência em sua comuna: por exemplo, ele proibia severamente a relação monogâmica. Gradativamente, seus integrantes começaram a questionar os ideais de propriedade coletiva e promiscuidade absoluta impostos pelo líder da Friedrechsholf.

Em 1990, a comuna se desintegrou e Mühl foi acusado de pedofilia. Diante disso, as apresentações do ex-performer dos Acionistas Vienenses ganharam grande repercussão no mundo da arte contemporânea, não porque seus atos revolucionassem aspectos do mundo da arte, mas porque serviram de alimento à "impressa marrom" e, consequentemente, ao establishment.

\section{Conclusão}

A temática que engloba a escatologia, o erótico e o horror na arte contemporânea foi tomada, por muitos artistas, como maneira de inverter a ordem simbólica repressora da cultura e ir ao encontro do Real. Mas por que essa fascinação pelo trauma e pela abjeção nos dias de hoje? Na perspectiva de Foster, existe uma insatisfação com o modelo textualista da cultura, assim como uma visão convencionalista da realidade, como se o Real, reprimido na pós-modernidade pós-estruturalista, houvesse retornado como traumático. E esse Real seria uma forma de ir contra o imaginário de uma fantasia consumista.

Grosso modo, tanto Žižek quanto Foster afirmam que na cultura contemporânea a verdade está no sujeito traumático, no abjeto, no corpo doente ou ferido. Segundo Foster, o corpo seria, sem dúvida, uma espécie de prova documental da verdade e testemunha contra o poder, mostrando que essa definição de verdade pode restringir nosso imaginário político ao campo da abjeção e do abjeto. Desse modo,

se existe um sujeito da história para o culto da abjeção, este não é o Trabalhador

\footnotetext{
20 Dois trabalhos de Otto Mühl foram expostos no museu do Louvre: Posséder et Détruire (2000) e La Peinture comme crime (2002); a partir de então, eles se fixaram nos cânones da história da arte.
} 
nem a Mulher nem a Pessoa de Cor, mas o Cadáver. E essa não é apenas uma política da diferença levada à indiferença; é uma política da alteridade levada à niquilidade" (FOSTER, 2014, p. 156).

Por fim, nas palavras de Foster:

\begin{abstract}
De um lado, na arte e na teoria do discurso do trauma dá continuidade, por outros meios, à crítica pós-estruturalista do sujeito, pois, repito, num registro psicanalítico não existe um sujeito do trauma; a posição é evacuada, e nesse sentido a crítica do sujeito é aqui extremamente radical. De outro lado, na cultura popular o trauma é tratado como um acontecimento que assegura o sujeito, e nesse registro psicológico o sujeito, embora perturbado, volta como testemunha, atestador, sobrevivente. Eis aí decerto um sujeito traumático, e ele tem autoridade absoluta, pois não se pode contestar o trauma de outrem: só se pode acreditar nele, até mesmo identificar-se com ele, ou não. No discurso do trauma, portanto, o sujeito é a um só tempo evacuado e elevado. E, dessa maneira, o discurso do trauma resolve magicamente dois imperativos contraditórios na cultura atual: a análise desconstrutivista e a política da identidade. Esse estranho renascimento do autor, essa condição paradoxal da autoridade ausente, é uma virada significativa na arte contemporânea, na crítica e na política cultural (FOSTER, 2014, p.157).
\end{abstract}

Em suma, a arte contemporânea foi capaz de estetizar a fascinação do objeto sublime que sustenta a dimensão da ideologia, mostrando sua ambivalência: o mesmo objeto que serve de fetiche pode ser visto como elemento crítico; como o objeto sem seus excedentes pode ser um encontro com o Real, o dejeto, e também um escudo que me protege contra o Real traumático.

\title{
Referências Bibliográficas
}

ADORNO, T.; HORKHEIMER, M. Dialética do Esclarecimento: fragmentos filosóficos. Tradução Guido Antonio de Almeida. Rio de Janeiro: Jorge Zahar, 2006.

BADIOU, A. O Século. Tradução Carlos Felício Silveira. São Paulo: Ideias \& Letras, 2007.

BENJAMIN, W. Obras Escolhidas II: Rua de mão única. Tradução Rubens Rodrigues Torres Filho e José Carlos Martins Barbosa. São Paulo: Brasiliense, 1995.

BEYST, S. FRIEDRICHSHOF: from the happening to the commune, and further still... about the transition from art to life. Disponivel em: dsites.net/english/muhl.htm.

BÜRGER, P. Teoria da Vanguarda. Tradução José Pedro Antunes. Rio de Janeiro: Cosac Naify, 2008. 
FOSTER, H. O retorno do real: A vanguarda no final do século XX. Trad. Célia Euvaldo. São Paulo: Cosac Naify, 2014.

Pós-Crítica. Disponível em: http://www.ppgav.eba.ufrj.br/wp-content/ uploads/2013/12/ae25_hal.pdf.

SIGMUND, F. "Divisão do ego no processo de defesa". In:Edição Standard das Obras psicológicas completas de Sigmund Freud, vol. XXIII. Rio de Janeiro: Imago, 1987c.

LACAN, J. Escritos. Tradução Vera Lucia Avellar Ribeiro. Rio de Janeiro: Jorge Zahar, 1998.

RIVERA, T. O avesso do imaginário. Rio de Janeiro: Cosac Naify, 2013.

SAFATLE, V. Cinismo e falência da crítica. São Paulo: Boitempo, 2008.

ŽIŽEK, S. Lacrimae Rerum. Tradução Isa Tavares e Ricardo Gozzi. São Paulo: Boitempo, 2009.

Bem-vindo ao Deserto do Real. Tradução Paulo César Castanheira. São Paulo: Boitempo, 2005. 